Galal Akasha Badrawy; Rina Banerjee; Anthony Walshaw Bateman; Laurence David Bell; Donald Francisco Bermingham; David Alan Berry; Martin Hugh Briscoe; Leslie Lawrence Burton; Stephen William Burton; Patrick John Byrne;

Isobel Hamilton Campbell; Richard Paul Caplan; Jane Elizabeth Carruthers; Joan Dorothy Anne Casserley; Howard Robert Cattell; See Yuen Chung; John Frederick Colgan; Miranda Philomena Conway; Jennifer Anne Crisp; Catherine Mary Elizabeth Crowe;

Tewfik Khalil Musa Daradkeh; Valerie Davidson; Mark Davis; Vivien Deacon; Noeleen Marie Devaney; David John Francis Dodwell; Wendy Dougal;

Ahmed Mounir Mohamed Mounir El-Asra; Marie Louise Ellis; Maura Pauline Judith Ellis; Dorothy Mary Eminson; Basem Tawfik Farid; Geoffrey Philip Clive Fosbrooke;

Timothy Patrick Noel Garvey; Mounir Megalli Georgui; Christopher Martin Gillespie; Guy Manning Goodwin; Stephen William Green;

Ahmed Mohammed Khalil Mohammed Haggag; Christine Garda Mary Hamblin; Victor John Harris; Norman Stewart Harvey; Richard Martin Hawley; Peter Haydn Smith; Kevin Joseph Healy; James Duncan Hendry; Lesley Ann Hewson; Paul Anthony Hogbin; Frank Holloway; Carmel Mary Hughes; Valerie Charlotte Hughes; Ismail Abdulla Ismail; Ann Pauline Jackson; Sandra Reid Johns; Maureen Johnson; Jeffrey Royle Jones; Selwyn Anthony Kaplan; David Graham Kingdon; Sriya Ranjanee Kulupana;

Joseph Keith Laybourn; Tze-Ming Leung; Jeremy Roy Lissamore; Hilary Lloyd; Danuta Maciejczak; Iain Roderick William Macleod; Caroline Margaret Marriott; John Christopher Martin; Roger Geoffrey Cadoux Martin;
Francis Gordon Oriwa Matete; Barry James Matthews; Christopher Norman Mayer; Elspeth Campbell McCue; Philip Bowden Mitchell; Nazar M. Mohammad Amin; Mungara Mohan Rao; Diana Patricia Morrison; Anne Muir; Evans Adam Pessa Muluka; Jonathan Derry Mumford;

Guruswamy Nagasundara Swamy; Laurence James Naismith; Rangaswamy Naveen Dayal; David Ritchie Neilson; Francis Mary Neilson; Hilary Nissenbaum; Mohammed Saleh Abdul Kader Noaman; Steven Novosel;

Mary Patricia Ann O'Donnell; Judith Mary O'Donovan; Olufemi Ramidele Olugbile; Daniel Noel O'Malley; Abraham Nonyelum Onuora; John William O'Riordan; David Arnold Orton; Oluwafemi Akinwumni Oyebode;

Timothy Francis Packer; Julie Parker; Renuka Liladhar Patel; Antonio Juan Jose Perez Gil; Bharati Phadke; Jennifer Gae Potter; Anne Power;

Gopalapillai Rajagopal; Jayasimha Murti Rao; Patricia Mary Robertson; Phillipos Robotis; Imelda Mary Ryan;

Mohammad Sanati; Gangadharan Sathyadevan; Jonathan Stewart Shapero; Noel Patrick Sheppard; Liyanage Francis Adolphus Silva; Ahmed Hamdy Mostafa Ahmed Soliman; Christopher William Stone; Mary Loonie Sweeney;

Alexander Anson Tait; Cornelia Thiels; Janine Margot Thomson; Stephen Jan Ticktin; John Spencer Tomkinson; Gordon James Turnbull;

Hanne Van Der Wel; Michael Wanigaratne; Jane Susan Warrington; Susan Penelope Wellstood-Eason; Alison Mary Wenzerul; Sheila Catherine Will; Peter Ashley Williams; Malcolm Raymond Wiseman; Chung-Kwong Wong; Linde Diana Wotton; Margo Mary Wrigley; Ka Kui Gabriel Yu; Anne Rosemary Zachary.

\title{
Extensions of Legal Aid Provisions to include Legal Representation of Detained Patients at Mental Health Review Tribunals
}

[The Public Policy Committee Working Party on the Mental Health (Amendment) Act thought that members of the College might be interested in the following Health Notice.]

\section{Summary}

This Notice notifies Health Authorities of the extension of the Legal Aid Scheme to include legal representation for all applicants to a Mental Health Review Tribunal (MHRT) from 1 December 1982 under the Assistance by Way of Representation (ABWOR) Scheme.

Background

1. In recent years the proportion of patients represented before a MHRT has increased considerably. Legal assistance under the Green Form Scheme is available to help patients and other applicants with limited financial resources to prepare their cases and covers all work carried out by a lawyer short of instituting proceedings. Advice and Assistance, however, does not cover legal representation at MHRT hearings (although some solicitors have been willing to appear at hearings without payment).

2. The Government has long recognized the merits of the case for providing legal representation to patients appearing before MHRTs. It has now decided that ABWOR should be made available for representation before MHRTs. Accordingly, the Lord Chancellor will bring forward the 
necessary regulations under Section $2 \mathrm{~A}$ of the Legal Aid Act 1974.

3. The introduction of ABWOR will have the effect of extending the Green Form Scheme to assistance given by a lawyer to an applicant in instituting and conducting proceedings, including representing a patient before a tribunal. ABWOR can only be given to a person who has the right to be represented before a tribunal, which under the present Rules does not include the patient when he or she is not the applicant. (Where the Minister has referred the case under Section 57 of the Mental Health Act 1959, or in the case of a restricted patient, where the Home Secretary has referred the case, the patient is considered to be the applicant.) This means that when the nearest relative is the applicant, they and not the patient, will be entitled to claim ABWOR.

\section{Procedure}

4. Before assistance of any kind may be given under the Green Form Scheme, the patient must undergo a simple assessment of resources carried out by his solicitor to ensure that he qualifies on financial grounds. In addition where ABWOR is sought the patient must obtain the approval of the Law Society.

5. The 'Green Forms' will be available from the Law Society Legal Aid local centres. A list of Legal Aid Centres in England and Wales is at Appendix $A^{*}$; the area covered by each centre is shown in Appendix $B^{*}$. In addition both hospital managers and any member of staff including the social workers may obtain advice from the centres to assist those detained patients who have no access to solicitors or legal advice.

\section{Action}

6. District Health Authorities, Special Health Authorities and Boards of Governors are required to draw this circular to the attention of all staff in their hospitals working with detained mental patients. In addition DHAs are asked to ensure that this circular is brought to the attention of all private mental nursing homes registered with their Authority under the Nursing Homes Act 1975, that is mental nursing homes in which mental patients may be detained.

"Copies of Appendices A and B may be obtained from the College.

\section{News Items}

\section{New Appolntments}

Following the retirement of Dr Edgar Udwin at the end of March, DR Jorn R. HAmiton is the new Medical Director of Broadmoor Hospital. Dr Hamilton currently holds a joint appointment as Consultant Psychiatrist at Broadmoor and Senior Lecturer in Forensic Psychiatry at the Institute of Psychiatry.

Dr Anthony Clare is to take over the Chair of Psychiatry at St Bartholomew's Hospital, London following the retirement of Professor Linford Rees. DR LAN F. Brockington is now Professor of Psychiatry at Queen Elizabeth Hospital, Birmingham, following the retirement of Sir William Trethowan.

\section{European Society of Child and Adolescent Psychiatry Prize}

Owing to the generosity of the Merck Foundation (Darmstadt), the European Society of Child and Adolescent Psychiatry is able to award a prize to a young research worker under 40 years of age. The prize (5,000 Swiss francs) will be awarded for a piece of scientific research in the field of child and adolescent psychiatry. On this occasion the topic is: 'Depression and depressive states in children and adolescents'.

Further information can be obtained from the President of the European Society of Child and Adolescent Psychiatry. Professor W. Bettschart, Av. de la Chabliere 5, 1004 Lausanne, Switzerland.

\section{Alcohol Education and Research Fund}

The Alcohol Education and Research Fund was created as a charitable foundation under the Licensing (Alcohol Education and Research) Act 1981. The Fund is available to finance projects within the United Kingdom for education and research and for novel forms of help to those with drinking problems, including offenders. The Fund is administered by the Alcohol Education and Research Council. (A list of various areas of interest for which grants will be particularly welcomed is available from the Council Secretary.) Further information may be obtained from: P. Beedle, Secretary to the AERC, Whittington House (Room 623), 19-30 Alfred Place, London WCIE 7EJ. 